\title{
Gastritis cystica profunda: a case report and literature review
}

\author{
Yinguo Du, Wei Zhang, Yu Ma, Zhebing Qiu \\ Department of Gastrointestinal Surgery, Shengzhou People's Hospital (the First Affiliated Hospital of Zhejiang University Shengzhou Branch), \\ Shengzhou, China \\ Correspondence to: Prof. Zhebing Qiu. Department of Gastrointestinal Surgery, Shengzhou People's Hospital (the First Affiliated Hospital of Zhejiang \\ University Shengzhou Branch), No. 666, Dangui Road, Shengzhou, China. Email: 723162107@qq.com.
}

\begin{abstract}
Gastric cystica profunda (GCP) is a rare disease characterized by multiple cystic lesions in the mucosa and/or submucosal layer. Usually, GCP occurs in stomachs that have previously been operated on. If there is no postoperative pathological results, it is challenging to diagnose GCP based on nonspecific clinical symptoms and imaging findings. This report aimed to provide a comprehensive overview of all cases of GCP reported to date. A comprehensive literature search was conducted for all reported GCP cases between 1972 and 2014. The keywords searched included "gastritis cystica profunda", "submucosal cysts of the stomach", and "heterotopic submucosal gastric glands". One retrospective case from our group was also reported and compared with those from the existing literature. A total of 52 cases were found including $37(71.2 \%)$ men and $15(28.8 \%)$ women $(\mathrm{M} / \mathrm{F}$ ratio $=2.5)$. The mean age of the patients was 59.9 (range, 39-91) years old. Among the cases, 58.8\% ( $n=30)$ of lesions were located in the gastric body, 25.5\% ( $n=13)$ of lesions were located in the fundus, $19.6 \%(n=9)$ of lesions were located in the antrum, and $3.9 \%(n=2)$ of lesions were located in the cardia, while 1 case was in the prepyloric lesion and 1 case was at the anastomotic site. Of the patients, $52 \%(n=26)$ had previously received gastric surgery. The main manifestations of GCP included abdominal pain $(\mathrm{n}=14,36.8 \%)$ and gastrointestinal bleeding (including hematemesis and melena, $\mathrm{n}=7,18.4 \%$ ). Only 4 of the 52 cases were diagnosed before surgery, and the rest were diagnosed through postoperative histopathologic examination. GCP is difficult to correctly diagnose preoperatively due to its relative rarity and lack of typical clinical symptoms. Histopathological examination should be used for correct diagnosis. Complete surgical removal of the GCP is widely considered as the best treatment option.
\end{abstract}

Keywords: Gastritis cystica profunda; gastric cystica profunda (GCP); hyperplastic cystic lesion; submucosal cysts of the stomach; heterotopic submucosal gastric

Submitted May 19, 2020. Accepted for publication Sep 08, 2020.

doi: 10.21037/apm-20-1253

View this article at: http://dx.doi.org/10.21037/apm-20-1253

\section{Introduction}

Gastric cystica profunda (GCP), a peculiar hyperplastic cystic lesion, was first described by Scott and Payne in 1947 (1). More than two decades later, Littler and Glibermann coined the term "gastritis cystica profunda" and suggested that the presence of cystically dilated gastric glands in the submucosa was a reactive, postsurgical condition (2). However, "gastritis cystica profunda" has since become the preferred term for the disease, because of its resemblance to a similar condition in the colon (3). GCP is a rare disease in clinical practice. There is no unified diagnostic standard at present. It often needs to be combined with a variety of auxiliary examinations for comprehensive diagnosis. At present, pathological examination of resected specimens is still the gold standard for the diagnosis of deep cystic gastritis. The pathological features of gastric propria were infiltrating into the deep or submucosa of gastric mucosa, cystic expansion of glands, connective tissue hyperplasia and inflammatory cells.

With the continuous development and improvement of endoscopic ultrasound (EUS), it plays an increasingly important role in the preoperative diagnosis of GCP, and has high diagnostic value. Under EUS, the typical 
imaging features of GCP were that the lesions originated from the gastric basal mucosa and gradually extended to the submucosa. Specific thickening of the gastric wall with local depth to the submucosa or even the irregular hypoechoic area of the muscularis propria were observed, but the mucosal surface was normal. It has been reported that there are three main forms of GCP in EUS (4): (I) anechoic (35.3\%).; (II) heterogeneous echo with thickened mucosa $(50 \%)$; (III) hypoechoic with vesicles (14.7\%). Because tumor markers such as carcinoembryonic antigen (CEA) and carbohydrate antigen 19-9 (CA19-9) may be expressed in the cystic fluid of GCP, the cyst fluid obtained by EUS guided fine needle aspiration biopsy (FNAB) can be used to differentiate GCP from gastric malignant tumor, but the diagnosis results should be treated objectively and cautiously (5).

Endoscopic resection can be the first choice for GCP diagnosis without other malignant lesions, including endoscopic mucosal resection (EMR) and endoscopic submucosal dissection (ESD). Compared with traditional surgical resection, endoscopic resection has the advantages of safety, less invasion and lower treatment cost. The most important thing is that it can better protect the function of the stomach with minimal trauma. Xu et al. (4) through the clinical study of 34 patients with GCP, the complete resection rate of ESD group (92\%) was significantly higher than that of EMR group (78\%), which indicated that ESD was more suitable for endoscopic treatment of GCP. 3.2 surgical resection with the increasing emphasis on the relationship between GCP and gastric malignant lesions, surgical resection has gradually become an important treatment for GCP (6-8), mainly including local tumor resection, subtotal gastrectomy and total gastrectomy. The authors believe that when the lesions can not be resected under endoscopy, or the existence of malignant lesions is highly suspected through endoscopy and related tissue biopsy, corresponding and active surgical treatment should be taken according to its location.

A minute number of GCP cases have been reported in more than half a century. The lesion is well known to be related to various factors acting in concert: first, a procedure that predisposes the patient to mucosal defects, such as surgery, biopsy, or polypectomy, and second, chronic ischemia and inflammation (9). Despite GCP is often considered to be a benign lesion, several studies have reported a correlation between GCP and gastric adenocarcinoma (10-12). The differentials for GCP should include gastrointestinal stromal tumor (GIST) (13), Ménétrier's disease $(14,15)$, inverted hyperplastic polyps (16), and other polypoid lesions. A case of GCP has been reported before (17), but unlike them, we report a case of GCP in an unoperated stomach and compare its clinical features, diagnosis, and treatment with another 51 published cases. We present the following article in accordance with the CARE reporting checklist (available at http://dx.doi. org/10.21037/apm-20-1253).

\section{Case presentation}

A 43-year-old woman underwent an endoscopic ultrasonography (EUS) after suffering from intermittent epigastric discomfort for almost a year. The EUS indicated the presence of a huge submucosal mass in the anterior wall of gastric antrum, which was diagnosed as a deep antrum cyst (Figures 1,2). The results of a physical examination of the patient showed no abnormalities, and her laboratory findings, including routine blood and tumor marker tests, were all within the normal range. Also, the patient's personal and family medical histories were unremarkable. Abdominal computed tomography (CT) showed an irregular hypodense mass measuring $1.3 \mathrm{~cm} \times 2.2 \mathrm{~cm}$ in the greater curvature of the stomach, and enhanced scanning showed mild to moderate enhancement in the center of the lesion, which was suspicious of GIST (Figure 3). To examine the lesion further, a magnetic resonance imaging (MRI) scan of the stomach was performed, and revealed marked irregular thickening of the gastric wall on the greater curvature of antrum, which was also suggestive of GIST (Figure 4).

Because GIST was highly suspected, the patient underwent a distal gastric resection (Billroth I). Gross pathologic examination revealed that the tumor was $2.5 \mathrm{~cm} \times$ $1.5 \mathrm{~cm}$ in size with a normal mucosal surface. Microscopic pathologic examination showed thickening of the muscularis and cystic downgrowth of the gastric glands into the submucosa of the stomach with low-grade dysplasia, which is consistent with gastritis cystica profunda (Figures 5). The patient was discharged after 12 days of hospitalization. After three months of follow-up, the patient was healthy with no signs of recurrence.

All procedures performed in studies involving human participants were in accordance with the ethical standards of the institutional and/or national research committee(s) and with the Helsinki Declaration (as revised in 2013). Written informed consent was obtained from all patients. 


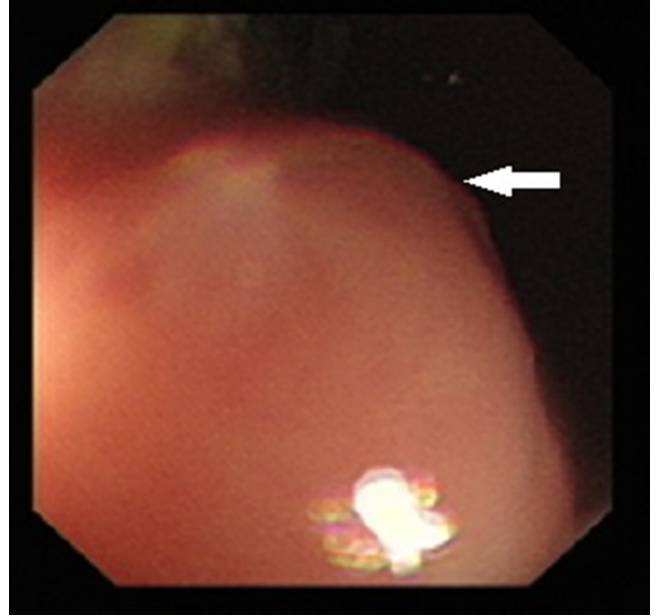

Figure 1 Gastroscopy revealed a subepithelial protruding mass (arrow) covered by normal mucosa in the anterior portion of the gastric antrum.

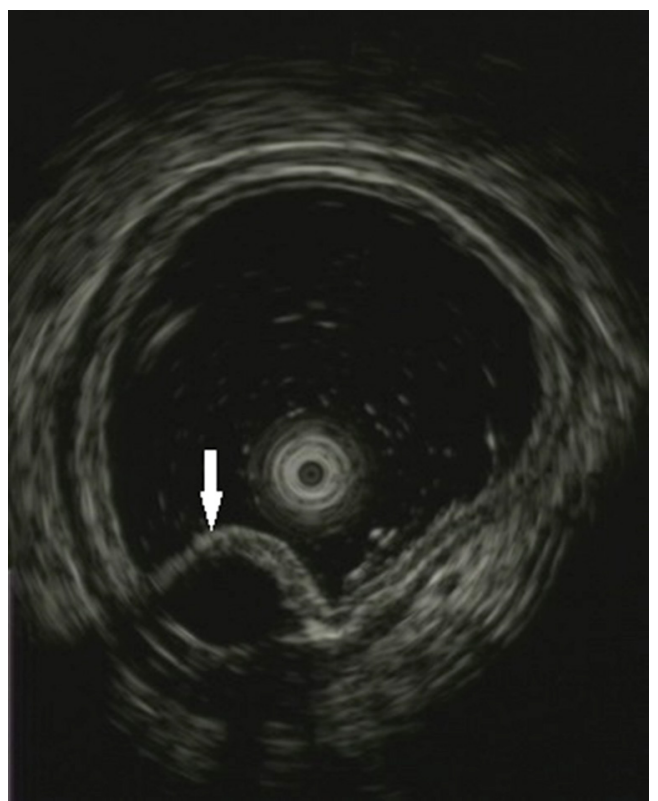

Figure 2 Endoscopic ultrasonography showed a homogeneous and hypoechoic mass measuring $1.0 \mathrm{~cm} \times 1.6 \mathrm{~cm}$ in size with an irregularly thickened wall in the submucosal layer of the stomach. The arrow points to the tumor.

\section{Literature review}

To date, 52 cases of GCP have been documented, including the case reported here. The clinical and treatment data of these cases are detailed in Table 1.

Among these 52 patients, 37 were men and 15 were

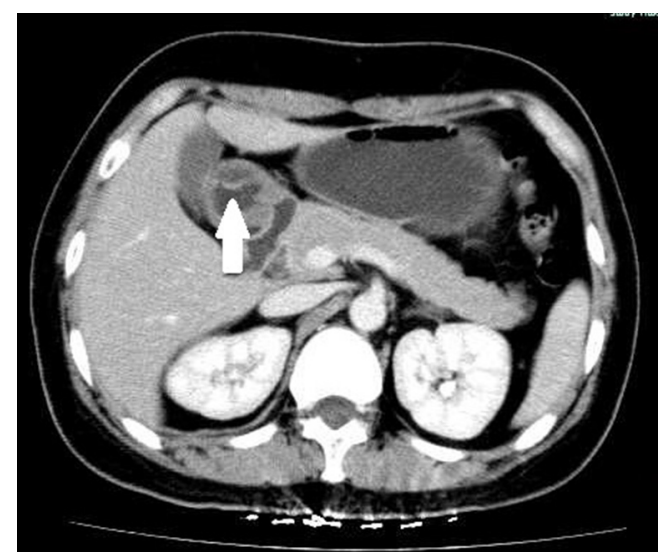

Figure 3 A contrast-enhanced CT scan of stomach revealed marked irregular thickening of the gastric wall on the greater curvature of the antrum (arrow), with mild to moderate enhancement.

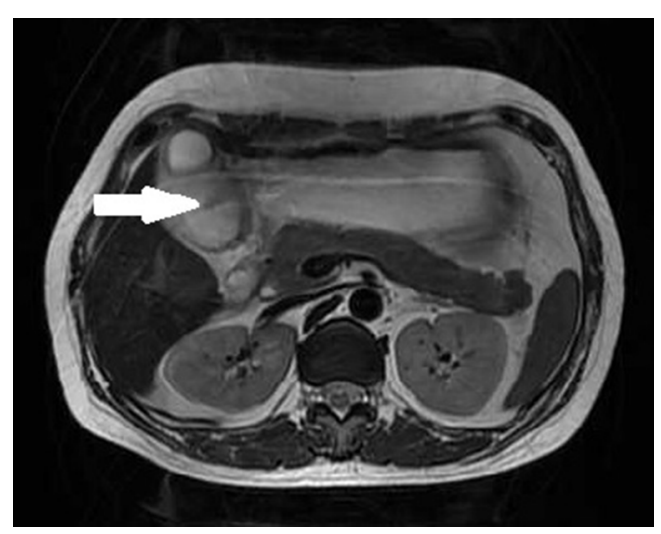

Figure 4 MRI images showing that the gastric wall on the greater curvature of the antrum was markedly irregularly thickened (arrow).

women (M:F ratio, 2.5:1). The patients had an overall mean age of 59.9 years (range: $39-91$ years) old. The majority of the cases $(74 \%)$ were over the age of 50 years old. The mean age of the female cases was 60.2 years (range: 39-79 years) old, and the mean age of the male cases was 60.3 years (range: 44-91 years) old. Only $52 \%$ of patients had a history of stomach surgery. Among the cases, 38 presented symptoms: GCP was an incidental finding in $28.9 \%(\mathrm{n}=11)$ of patients, and the main clinical manifestations were abdominal pain $(\mathrm{n}=14,36.8 \%)$, followed by gastrointestinal bleeding $(\mathrm{n}=7,18.4 \%)$, weight loss $(\mathrm{n}=4,10.5 \%)$, and anemia $(\mathrm{n}=4$, $10.5 \%)$. Less common symptoms included anorexia $(\mathrm{n}=2$, $5.3 \%)$, epigastric discomfort $(\mathrm{n}=2,5.3 \%)$, vomiting $(\mathrm{n}=2$, $5.3 \%)$, nausea ( $\mathrm{n}=1,2.6 \%)$, belching and mild dysphagia $(\mathrm{n}=1,2.6 \%)$, fatigue $(\mathrm{n}=1,2.6 \%)$, fullness $(\mathrm{n}=1,2.6 \%)$, 

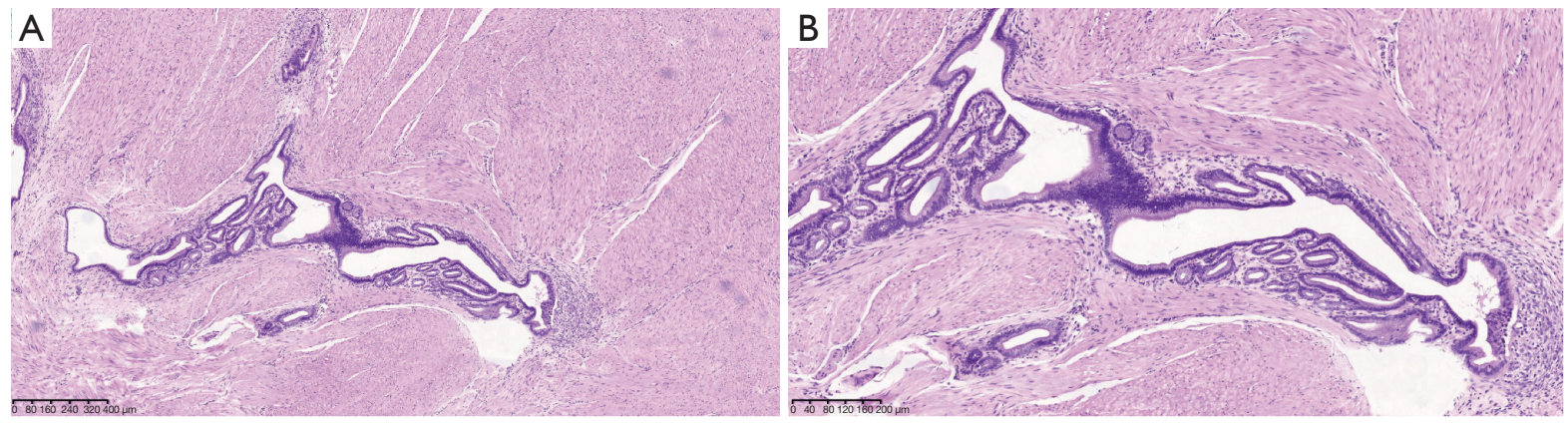

Figure 5 Histological examination of the nodular lesions showed cystically dilated gastric glands penetrating into the submucosa and muscularis propria, some with mild dysplastic changes. Hematoxylin and eosin staining: (A) $\times 50$; (B) $\times 400$.

Table 1 All published cases of gastritis cystica profunda from 1972-2014

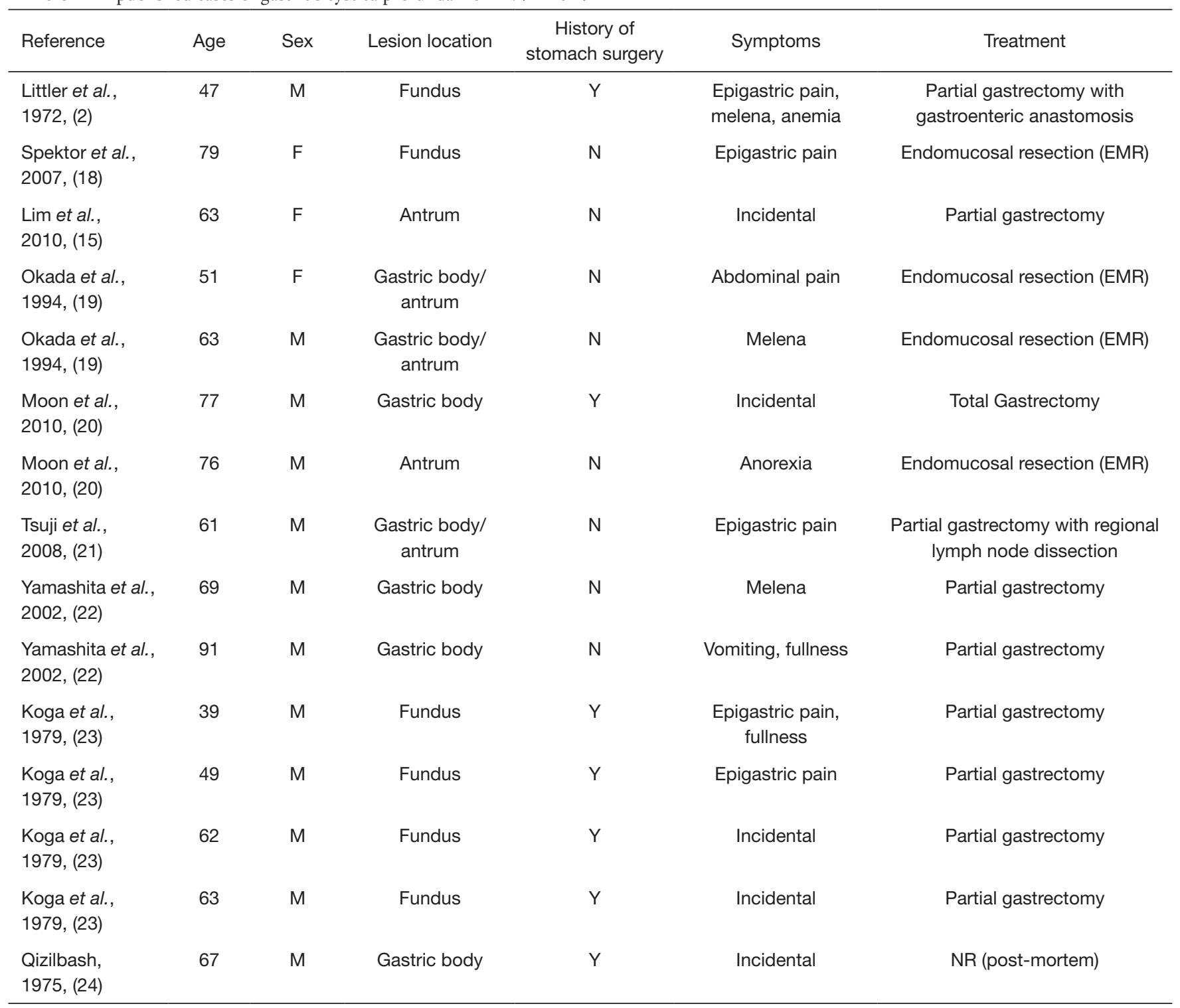

Table 1 (continued) 
Table 1 (continued)

\begin{tabular}{|c|c|c|c|c|c|c|}
\hline Reference & Age & Sex & Lesion location & $\begin{array}{c}\text { History of } \\
\text { stomach surgery }\end{array}$ & Symptoms & Treatment \\
\hline $\begin{array}{l}\text { Fonde et al., } \\
1986,(9)\end{array}$ & 50 & M & $\begin{array}{l}\text { Gastric body/ } \\
\text { antrum }\end{array}$ & $\mathrm{N}$ & $\begin{array}{l}\text { Epigastric pain, } \\
\text { fullness, weight loss, } \\
\text { hematemesis }\end{array}$ & $\begin{array}{l}\text { Total gastrectomy with Roux- } \\
\text { en-Y esophagojejunostomy }\end{array}$ \\
\hline $\begin{array}{l}\text { Park et al., } \\
2001,(25)\end{array}$ & 44 & $\mathrm{~F}$ & Fundus & $\mathrm{N}$ & Epigastric pain & Polypectomy \\
\hline $\begin{array}{l}\text { Tomizuka et al., } \\
2008,(27)\end{array}$ & 78 & M & Cardia & $\mathrm{Y}$ & Incidental & $\begin{array}{l}\text { Partial gastrectomy with Roux- } \\
\text { en-Y esophagojejunostomy }\end{array}$ \\
\hline $\begin{array}{l}\text { Itte et al., } \\
2008,(28)\end{array}$ & 50 & M & Fundus & $\mathrm{Y}$ & $\begin{array}{l}\text { Epigastric pain, } \\
\text { hematemesis, } \\
\text { anemia }\end{array}$ & Surveillance \\
\hline $\begin{array}{l}\text { Wu et al., } \\
1994,(30)\end{array}$ & 58 & $\mathrm{~F}$ & Fundus & $\mathrm{N}$ & Anorexia, weight loss & $\begin{array}{l}\text { Total gastrectomy with Roux- } \\
\text { en-Y esophagojejunostomy }\end{array}$ \\
\hline $\begin{array}{l}\text { Franzin et al., } \\
1981,(3)^{\star}\end{array}$ & $42-71$ & $12 \mathrm{M}: 2 \mathrm{~F}$ & Gastric body & Y & NR & NR \\
\hline $\begin{array}{l}\text { Laratta et al., } \\
2012,(13)\end{array}$ & 39 & $\mathrm{~F}$ & Antrum & $\mathrm{N}$ & Incidental & $\begin{array}{l}\text { Partial gastrectomy with Roux- } \\
\text { en-Y esophagojejunostomy }\end{array}$ \\
\hline $\begin{array}{l}\text { Lee et al., } \\
2013,(31)\end{array}$ & 48 & $\mathrm{~F}$ & NR & $\mathrm{N}$ & Incidental & Endoscopic polypectomy \\
\hline $\begin{array}{l}\text { Xu et al., } \\
2011,(34)\end{array}$ & 48 & $\mathrm{~F}$ & Gastric body & $\mathrm{N}$ & $\begin{array}{l}\text { Diarrhea, nausea, } \\
\text { anorexia and weight } \\
\text { loss }\end{array}$ & $\begin{array}{c}\text { Remote subtotal } \\
\text { gastrectomy with a Billroth II } \\
\text { gastrojejunostomy }\end{array}$ \\
\hline $\begin{array}{l}\text { Effenberger } \\
\text { et al., 2014, (35) }\end{array}$ & 79 & M & Anastomotic site & Y & Progressive fatigue & Surveillance \\
\hline $\begin{array}{l}\text { Lee et al., } \\
2013 \text { (16) }\end{array}$ & 77 & M & Gastric body & Y & Incidental & $\begin{array}{l}\text { Endoscopic submucosal } \\
\text { dissection }\end{array}$ \\
\hline $\begin{array}{l}\text { Deery et al., } \\
2012,(11)\end{array}$ & 70 & $\mathrm{~F}$ & Gastric body & $\mathrm{N}$ & $\begin{array}{l}\text { Belching and mild } \\
\text { dysphagia }\end{array}$ & $\begin{array}{l}\text { Proximal gastrectomy and } \\
\text { extended D2 lymphadenectomy } \\
\text { with splenectomy and total } \\
\text { omentectomy }\end{array}$ \\
\hline $\begin{array}{l}\text { Machicado } \\
\text { et al., 2014, (36) }\end{array}$ & 61 & $\mathrm{~F}$ & Gastric body & $\mathrm{N}$ & Dull epigastric pain & Partial gastrectomy \\
\hline $\begin{array}{l}\text { Alkimawi et al., } \\
2014,(37)\end{array}$ & 55 & $\mathrm{~F}$ & Fundus & $\mathrm{N}$ & $\begin{array}{l}\text { Epigastric abdominal } \\
\text { pain }\end{array}$ & Surveillance \\
\hline
\end{tabular}

Table 1 (continued) 
Table 1 (continued)

\begin{tabular}{|c|c|c|c|c|c|c|}
\hline Reference & Age & Sex & Lesion location & $\begin{array}{c}\text { History of } \\
\text { stomach surgery }\end{array}$ & Symptoms & Treatment \\
\hline $\begin{array}{l}\text { Kim et al., } \\
2012,(38)\end{array}$ & 50 & $M$ & Gastric body & NR & Incidental & Radical total gastrectomy \\
\hline $\begin{array}{l}\text { Matsumoto } \\
\text { et al., 2012, (12) }\end{array}$ & 51 & $\mathrm{~F}$ & Prepyloric & $\mathrm{N}$ & Vomiting & Distal gastrectomy \\
\hline $\begin{array}{l}\text { Wang et al., } \\
2014,(39)\end{array}$ & 63 & $M$ & Antrum & $\mathrm{N}$ & $\begin{array}{l}\text { Intermittent } \\
\text { epigastric discomfort }\end{array}$ & Surgical resection \\
\hline $\begin{array}{l}\text { Current study, } \\
2014\end{array}$ & 43 & $\mathrm{~F}$ & Antrum & $\mathrm{N}$ & $\begin{array}{c}\text { Intermittent } \\
\text { epigastric discomfort }\end{array}$ & Distal gastrectomy \\
\hline
\end{tabular}

*, Franzin et al., 1,981 describes 14 cases of GCP based on histological findings alone. The authors did not describe the clinical characteristics or treatment of the patients. The patients were aged 42-71 years old, and 12 were male and 2 were female. All lesions were located in stomach body. M, male; F, female; Y, yes; N, no; NR, not recorded.

and hypoalbuminemia $(\mathrm{n}=1,2.6 \%)$. The most common anatomic GCP location was the gastric body $(n=30$, $58.8 \%)$, followed by the fundus $(n=13,25.5 \%)$, antrum $(n=9,19.6 \%)$, and cardia $(n=2,3.9 \%)$; some lesions were located at the anastomotic site, in the prepyloric lesion, and the junction of the gastric body with the antrum or fundus. The treatment plans of 37 cases were available, and treatments included partial gastrectomy $(n=20,54.1 \%)$, complete surgical removal of the stomach $(n=5,13.5 \%)$, endomucosal resection $(n=5,13.5 \%)$, surveillance $(n=3$, $8.1 \%)$, polypectomy $(\mathrm{n}=2,5.4 \%)$, and medication with a proton pump inhibitor $(n=1,2.7 \%)$. One case was without detailed surgical approach.

\section{Discussion}

The etiology and pathogenesis of GCP have yet to be fully illuminated. In 1975, Chakravorty (40) put forward GCP as a congenital disease because it is developed by some individuals with no gastric ulcers or history of gastric surgery. However, more and more researchers support the idea that acquired factors play a prominent role in the development of GCP. Franzin (3), who in 1981 studied a particular case of GCP, concluded that the presence of cystically dilated gastric glands in the submucosa was a reactive, postsurgical condition caused by the integrity of the gastric mucosa being disrupted. Moreover, in 1986, Fonde (9) pointed out that GCP developed secondary to ischemia, chronic inflammation, and stimulation by a foreign body (surgical sutures). Potassium voltage-gated channel subfamily E member 2 (KCNE2) is one of the vital subunits of apical potassium channels in parietal cells. In 2010, Roepke (41) achieved a breakthrough, finding that all $11 \mathrm{KCNE} 2$ gene knockout mice in their study exhibited a severe gastric preneoplastic phenotype comprising GCP, while none of the 5 mice in the control group developed GCP. This suggested a relationship between KCNE2 disruption and the development of GCP and gastric neoplasia. Additionally, a recent study (10) showed that KCNE2 expression was reduced in human gastric cancer tissues, which is in line with Roepke's finding that KCNE2 expression was negatively correlated with the formation of gastric cancer. In 2012, Kim (38) reported a case of GCP associated with gastric carcinoma with lymphoid stroma and observed that Epstein-Barr virus (EBV) in situ hybridization revealed a positive reaction at the dysplastic area as well as the carcinoma area. These findings suggest that GCP is a precancerous lesion and $\mathrm{EBV}$ infection plays an important role in dysplastic change. Also, a review of 10,728 patients with gastric cancer who underwent gastric cancer surgery by Choi (42) found that the EBV-positive rate was significantly higher in the GCP group $(31.1 \%)$ than in the non-GCP group (5.8\%), which indicated that GCP was strongly associated with EBV-positive gastric cancers, and it was highly suspected as to be a premalignant lesion. Finally, experiments (43) have also shown that animals predisposed to Helicobacter infection develop not only secondary GCP but also subsequent primary gastric carcinoma. 
Whether or not GCP is malignant is still controversial. Historically, the activity of submucosal glands in GCP has not been thought to represent cancer. However, GCP has been reported to coexist with gastric adenocarcinoma $(10,12)$, Ménétrier's disease $(14,15)$, and gastric carcinoma with lymphoid stroma (38). A Japanese study (26) performed an immunohistochemical analysis on a GCP gross specimen and described elevated expression of Ki-67, p53, and p21 in GCP lesions, which was indicative of increased epithelial proliferation and increased DNA repair, and thus might explain the etiology of GCP as the precursor of gastric cancer.

A total of 57 GCP cases were retrospectively collected including 1 case from our hospital and 51 cases from 32 reports published between 1972 and 2014. GCP was significantly associated with older age and male gender (71.1\%, M:F ratio, 2.5:1). GCP is known to occur most commonly in patients who have undergone gastric surgery. However, in our study, we did not find much difference in the percentages of patients with or without a history of gastric surgery ( $52 \%$ versus $48 \%$ ).

Clinically, GCP patients experience abdominal pain, followed by gastrointestinal bleeding, weight loss, and anemia. Rarer symptoms include nausea, epigastric discomfort, vomiting, belching and mild dysphagia, anorexia, fatigue, fullness, and hypoalbuminemia. GCP was found incidentally in more than one-quarter of cases, and sometimes, the lesion could be found in an emergency situation as it could lead to haematemesis $(28,29)$.

GCP is a rare condition with non-specific symptoms and radiographic features, which makes its diagnosis without definitive surgical resection difficult. Physical examinations and laboratory studies often fail to produce significant findings. In CT and MRI imaging examinations, GCP presents as a polypoid mass. Unspecific circumferential thickening of the gastric wall with cystic changes in appearance on CT scan and MRI has not been reported previously. In the current study, a MRI scan was also performed and demonstrated that the gastric wall on the greater curvature of the antrum was markedly irregularly thickened, with high signals on diffusion weighted imaging (DWI) and no perigastric or periesophageal lymph nodes identified. The findings of CT and MRI are not diagnostic of GCP, as they mimic those of other hyperproliferative conditions. However, Wu once reported a case in which the features of GCP were preoperatively evaluated by CT (30). The differential diagnosis of GCP should include GIST, gastric adenocarcinoma and other submucosal lesions.
Compared to gastric adenocarcinoma, GCP rarely presents with weight loss, cachexia or high enhancement in CT examination. Radiographically, GIST and GCP both appear as hypoechoic, intramural polypoid masses with cystic changes (13). EUS examination should be conducted to obtain more information to further investigate the mucosal pathology. The most frequent EUS feature of GCP was multiple anechoic cystic spaces/cysts in the submucosa of those cases (36). Further, the diagnostic process can be improved by the use of EUS fine needle aspiration (FNA). Chung (44) considered EUS to be an effective diagnostic tool for evaluating and differentiating GCP from the protruding and elevated gastric lesion, with $88.9 \%$ sensitivity and a $100 \%$ positive rate. With the development of endoscopic techniques in recent years, four patients have been preoperatively diagnosed by endoscopic mucosal resection (EMR) or endoscopic mucosal resection (ESD).

Pathological examination is a monopolistic diagnostic procedure for evaluating GCP. Histologically, GCP is characterized by the elongation of the gastric foveolae with hyperplasia and cystic dilatation of the gastric glands, extending into the submucosal layer. Occasionally, mild dysplasia is present, as with the current case.

Given the rarity of the GCP and the difficulty in diagnosing it preoperatively, a defined treatment strategy has not been well described. Of the 37 cases for whom specific treatment plans are available to date, only 4 patients did not receive surgical treatment: 1 patient received medication with a proton pump inhibitor, and the other 3 were in surveillance. Almost $89.2 \%$ of the patients underwent surgical resection, as did our current case. The most frequently used surgical treatment is partial gastrectomy, followed by complete removal of the stomach, endomucosal resection, and polypectomy. The location of the lesion is well known to determine the surgical approach. In the current study, because the lesion was located in the antrum, distal gastrectomy with Billroth I gastrojejunostomy was performed. Currently, since an increasing number of reports have tended to support the potential malignancy of GCP, gastrectomy or total gastrectomy is regarded as the most recommended approach for relieving the symptoms and curing the disease. However, reflux after surgery, foreign bodies (sutures), and gastric mucosa damage may lead to the development of GCP, which requires an appropriate surgical plan and close follow-up. Furthermore, ESD and EMR have emerged as new treatment options along with the advantage in minimally invasive approaches. However, according to a report published in 2011, these 
surgical procedures may facilitate the deep misplacement of the gastric glands into the muscularis propria; the report described how after three attempts to remove the polyp endoscopically, GCP recurred within short period and a gastric sleeve resection was eventually performed (33).

Generally, the prognosis of GCP is fair if the condition does not coexist with gastric adenocarcinoma, Menetrier's disease, gastric lymphoma, or other malignant diseases. The rate of recurrence is not well studied for GPC. To date, two cases of recurrence have been reported after surgical resection $(33,39)$. Meanwhile, a 10-year follow-up of a case of GCP in an unoperated patient revealed low-grade dysplasia, and the sizes of both the GCP and the adenoma overlying had increased during the follow-up period (45).

\section{Conclusions}

In conclusion, while complete removal of the lesion using established surgical oncology principles is widely recommended as the best treatment for GCP, there is little difference between the treatments for GCP patients with or without a surgical history. GCP is often confused with other submucosal gastric lesions without typical manifestations. The most common presenting symptom of GCP is abdominal pain, and EUS is seemingly the most effective approach for investigating the condition. Meanwhile, imaging examination with CT and MRI supplies limited information. Future studies are needed to elucidate the natural history of this disease process and its malignant potential; thus, more evidence-based treatment strategies are warranted.

\section{Acknowledgments}

Thank you very much for the technical support of Guangzhou Yujia Biological Technology Co., Ltd. Funding: None.

\section{Footnote}

Reporting Checklist: The authors have completed the CARE reporting checklist. Available at http://dx.doi.org/10.21037/ apm-20-1253

Conflicts of Interest: All authors have completed the ICMJE uniform disclosure form (available at http://dx.doi. org/10.21037/apm-20-1253). The authors have no conflicts of interest to declare.
Ethical Statement: The authors are accountable for all aspects of the work in ensuring that questions related to the accuracy or integrity of any part of the work are appropriately investigated and resolved. All procedures performed in studies involving human participants were in accordance with the ethical standards of the institutional and/or national research committee(s) and with the Helsinki Declaration (as revised in 2013). Written informed consent was obtained from all patients.

Open Access Statement: This is an Open Access article distributed in accordance with the Creative Commons Attribution-NonCommercial-NoDerivs 4.0 International License (CC BY-NC-ND 4.0), which permits the noncommercial replication and distribution of the article with the strict proviso that no changes or edits are made and the original work is properly cited (including links to both the formal publication through the relevant DOI and the license). See: https://creativecommons.org/licenses/by-nc-nd/4.0/.

\section{References}

1. Scott HW, Payne TP. Diffuse congenital cystic hyperplasia of stomach clinically simulating carcinoma; report of a case. Bull Johns Hopkins Hosp 1947;81:448-55.

2. Littler ER, Gleibermann E. Gastritis cystica polyposa. (Gastric mucosal prolapse at gastroenterostomy site, with cystic and infiltrative epithelial hyperplasia). Cancer-Am. Cancer 1972;29:205-09.

3. Franzin G, Novelli P. Gastritis cystica profunda. Histopathology 1981;5:535-47.

4. Xu G, Peng C, Li X, et al. Endoscopic resection of gastritis cystica profunda: preliminary experience with 34 patients from a single center in China. Gastrointest Endosc 2015;81:1493-98.

5. Park CH, Park JM, Chan KJ, et al. Early gastric cancer associated with gastritis cystica polyposa in the unoperated stomach treated by endoscopic submucosal dissection. Gastrointest Endosc 2009;69:e47-50.

6. Xu G, Qian J, Ren G, et al. A case of gastritis cystica profunda. Ir J Med Sci 2011;180:929-30.

7. Yu XF, Guo LW, Chen ST, et al. Gastritis cystica profunda in a previously unoperated stomach: a case report. World J Gastroenterol 2015;21:3759-62.

8. Kurland J, DuBois S, Behling C, et al. Severe upper-GI bleed caused by gastritis cystica profunda. Gastrointest Endosc 2006;63:716-17.

9. Fonde EC, Rodning CB. Gastritis cystica profunda. Am J 
Gastroenterol 1986;81:459-64.

10. Kuwahara N, Kitazawa R, Fujiishi K, et al. Gastric adenocarcinoma arising in gastritis cystica profunda presenting with selective loss of KCNE2 expression. World J Gastroenterol 2013;19:1314-17.

11. Deery S, Yates R, Hata J, et al. Gastric adenocarcinoma associated with gastritis cystica profunda in an unoperated stomach. Am Surg 2012;78:E379-80.

12. Matsumoto $T$, Wada $M$, Imai $Y$, et al. A rare cause of gastric outlet obstruction: gastritis cystica profunda accompanied by adenocarcinoma. Endoscopy 2012;44 Suppl 2 UCTN:E138-39.

13. Laratta JL, Buhtoiarova TN, Sparber LS, et al. Gastritis Cystica Profunda: A Rare Gastric Tumor Masquerading as a Malignancy. Surg Sci 2012;3:158-64.

14. Soares JB, Bastos P, Goncalves R. Menetrier disease with antrum polyposis and gastritis cystica profunda. Endoscopy 2012;44 Suppl 2 UCTN:E56-57.

15. Lim JK, Jang YJ, Jung MK, et al. Menetrier disease manifested by polyposis in the gastric antrum and coexisting with gastritis cystica profunda. Gastrointest. Endosc 2010;72:1098-100.

16. Lee SJ, Park JK, Seo HI, et al. A case of gastric inverted hyperplastic polyp found with gastritis cystica profunda and early gastric cancer. Clin Endosc 2013;46:568-71.

17. Yu XF, Guo LW, Chen ST, et al. Gastritis cystica profunda in a previously unoperated stomach: a case report. World J Gastroenterol 2015;21:3759-62.

18. Béchade D, Desramé J, Algayres JP. Gastritis cystica profunda in a patient with no history of gastric surgery. Endoscopy 2007;39 Suppl 1:E80-1.

19. Okada M, Iizuka Y, Oh K, et al. Gastritis cystica profunda presenting as giant gastric mucosal folds: the role of endoscopic ultrasonography and mucosectomy in the diagnostic work-up. Gastrointest Endosc 1994;40:640-4.

20. Moon SY, Kim KO, Park SH, et al. [Gastritis cystica profunda accompanied by multiple early gastric cancers]. Korean J Gastroenterol 2010;55:325-30.

21. Tsuji T, Iwahashi M, Nakamori M, et al. Multiple early gastric cancer with gastritis cystica profunda showing various histological types. Hepatogastroenterology 2008;55:1150-52.

22. Yamashita $M$, Hirokawa $M$, Nakasono $M$, et al. Gastric inverted hyperplastic polyp. Report of four cases and relation to gastritis cystica profunda. Apmis 2002;110:717-23.

23. Koga S, Watanabe H, Enjoji M. Stomal polypoid hypertrophic gastritis: a polypoid gastric lesion at gastroenterostomy site. Cancer 1979;43:647-57.

24. Qizilbash AH. Gastritis cystica and carcinoma arising in old gastrojejunostomy stoma. Can Med Assoc J 1975;112:1432-33.

25. Park JS, Myung SJ, Jung HY, et al. Endoscopic treatment of gastritis cystica polyposa found in an unoperated stomach. Gastrointest Endosc 2001;54:101-3.

26. Mitomi H, Iwabuchi K, Amemiya A, et al.

Immunohistochemical analysis of a case of gastritis cystica profunda associated with carcinoma development. Scand J Gastroenterol 1998;33:1226-29.

27. Tomizuka T, Mazaki T, Mado K, et al. A case of gastritis cystica profunda. Surgery 2008;143:449-50.

28. Itte V, Mallick IH, Moore PJ. Massive gastrointestinal haemorrhage due to gastritis cystica profunda. Cases J 2008;1:85.

29. Kurland J, DuBois S, Behling C, et al. Severe upper-GI bleed caused by gastritis cystica profunda. Gastrointest Endosc 2006;63:716-17.

30. Wu MT, Pan HB, Lai PH, et al. CT of gastritis cystica polyposa. Abdom Imaging 1994;19:8-10.

31. Lee TH, Lee JS, Jin SY. Gastritis cystica profunda with a long stalk. Gastrointest. Endosc 2013;77:821-22, 822.

32. Lee MS, Cho BS, Park JS, et al. Premalignant lesion of heterotopic pancreas combined with gastritis cystica profunda in gastric fundus. J Gastrointestin Liver Dis 2013;22:337-40.

33. Greywoode G, Szuts A, Wang LM, et al. Iatrogenic deep epithelial misplacement ("gastritis cystica profunda") in a gastric foveolar-type adenoma after endoscopic manipulation: a diagnostic pitfall. Am J Surg Pathol 2011;35:1419-21.

34. Xu G, Qian J, Ren G, et al. A case of gastritis cystica profunda. Ir J Med Sci 2011;180:929-30.

35. Effenberger M, Steinle H, Offner FA, et al. Holes in gastric mucosa in upper gastrointestinal endoscopy. Eur J Gastroenterol Hepatol 2014;26:676-78.

36. Machicado J, Shroff J, Quesada A, et al. Gastritis cystica profunda: Endoscopic ultrasound findings and review of the literature. Endosc Ultrasound 2014;3:131-4.

37. Alkimawi KA, Shuja A. A rare precursor of gastric tumor. Gastroenterol Rep (Oxf) 2014;2:320-22.

38. Kim L, Kim JM, Hur YS, et al. Extended gastritis cystica profunda associated with Epstein-Barr virus-positive dysplasia and carcinoma with lymphoid stroma. Pathol Int 2012;62:351-55.

39. Wang L, Yan H, Cao DC, et al. Gastritis cystica profunda recurrence after surgical resection: 2-year follow-up. 
World J. Surg. Oncol 2014;12:133.

40. Chakrovorty RC, Schatzki PF. Gastric cystic polyposis. Am J Dig Dis 1975;20:981-89.

41. Roepke TK, Purtell K, King EC, et al. Targeted deletion of Kcne2 causes gastritis cystica profunda and gastric neoplasia. PLoS One 2010;5:e11451.

42. Choi MG, Jeong JY, Kim KM, et al. Clinical significance of gastritis cystica profunda and its association with EpsteinBarr virus in gastric cancer. Cancer 2012;118:5227-33.

43. Wang TC, Dangler CA, Chen D, et al. Synergistic interaction between hypergastrinemia and Helicobacter infection in a mouse model of gastric cancer.

Cite this article as: Du Y, Zhang W, Ma Y, Qiu Z. Gastritis cystica profunda: a case report and literature review. Ann Palliat Med 2020;9(5):3668-3677. doi: 10.21037/apm-20-1253
Gastroenterology 2000;118:36-47.

44. Chung IK, Kim EJ, Kim DJ, et al. 4541 Clinical significance of gastritis cystica polyposa and role of endoscopic ultrasonography. Gastrointest Endosc 2000;51:B163.

45. Kim JH, Jang SY, Hwang JA, et al. [A ten-year follow-up of a case with gastric adenoma accompanied with gastritis cystica profunda treated by endoscopic submucosal dissection]. Korean J Gastroenterol 2012;59:366-71.

(English Language Editor: J. Reynolds) 